\title{
Genetic mutations and expression of p53 in non-invasive breast lesions
}

\author{
XIAOYUN MAO $^{1}$, CHUIFENG FAN $^{2}$, JING WEI $^{1}$, FAN YAO $^{1}$ and FENG JIN ${ }^{1}$ \\ ${ }^{1}$ Department of Surgical Oncology, Research Unit of General Surgery, Department of Breast Surgery, \\ the First Affiliated Hospital of China Medical University; ${ }^{2}$ Department of Pathology, the First Affiliated Hospital \\ and College of Basic Medical Sciences of China Medical University, Shenyang 110001, P.R. China
}

Received June 10,2010; Accepted August 2, 2010

DOI: $10.3892 / \mathrm{mmr} .2010 .353$

\begin{abstract}
Breast carcinogenesis results from the accumulation of numerous somatic genetic alterations. Although mutations of the tumor suppressor gene p53 are among the most common alterations identified in invasive breast carcinomas, it is not clear whether its alteration occurs frequently in non-invasive breast lesions, including usual ductal hyperplasia (UDH), atypical ductal hyperplasia (ADH) and ductal carcinoma in situ (DCIS). p53 mutations were examined in 140 cases of non-invasive breast lesions, including UDH, ADH and DCIS, by high-resolution melting (HRM), followed by DNA sequence analysis. Two hundred and forty cases of non-invasive breast lesions were subjected to the immunohistochemical staining of p53 protein. The HRM and sequencing analysis demonstrated that the positive rates of p53 mutation were $0.0,12.7$ and $21.6 \%$ in $\mathrm{UDH}, \mathrm{ADH}$ and DCIS, respectively. p53 protein expression was detected in none of the UDH, $14.6 \%$ of the ADH and $31.4 \%$ of the DCIS samples. Statistically, p53 mutation and protein accumulation gradually increased from UDH to ADH and to DCIS $(\mathrm{P}<0.05)$. There was a significantly positive association between p53 mutations and expression in these samples. p53 mutations and accumulation occur in non-invasive breast lesions, including $\mathrm{ADH}$ and DCIS, and may represent early events in breast carcinogenesis.
\end{abstract}

\section{Introduction}

The p53 tumor suppressor gene is thought to play a central role in protecting against the development of cancer. As a transcription factor, its encoding protein is a master switch that coordinates and concentrates a plethora of stress signals and transforms them into a series of responses, such as apoptosis

Correspondence to: Professor Feng Jin, Department of Surgical Oncology, Research Unit of General Surgery, Department of Breast Surgery, the First Affiliated Hospital of China Medical University, Liaoning, Shenyang 110001, P.R. China

E-mail: jinfeng66cn@hotmail.com

Key words: non-invasive breast lesions, p53 mutation, highresolution melting, p53 expression, immunohistochemistry or cell cycle arrest in response to DNA damage, thereby maintaining genetic stability in the organism (1). Mutations in p53 inactivating its function are frequently found in both familial and sporadic human cancers. More than $50 \%$ of human cancers harbor mutations in p53, and the p53 pathway is otherwise inactivated in most of the remaining cancers. In animal models, loss or mutation of p53 leads to a predisposition to a range of spontaneous and induced tumors, highlighting its protective role as a barrier to tumor development (2). Although p53 inactivation in human cancer is a complex process, depending on the tissue type, p53 dysfunction may disorder the biological events of cancer cells and give rise to their aggressive phenotypes, poor patient survival and resistance to treatment (2-6). The molecular genetic profile of p53 alterations has been well characterized in invasive breast cancer (6-8). However, only a few studies have investigated p53 alterations in non-invasive breast lesions, including usual ductal hyperplasia (UDH), atypical ductal hyperplasia (ADH) and ductal carcinoma in situ (DCIS). Moreover, the findings of these studies differed significantly, in particular in the case of ADH.

At present, there are several long-standing methods available for the detection of mutations in oncogenes and tumor suppressor genes, including direct sequencing and singlestrand conformation polymorphism (SSCP) of PCR, both of which are time-consuming procedures and require skill to interpret the results (9). High resolution melting (HRM) is a novel simple homogeneous close-tube and post-PCR method that enables genomic researchers to analyze genetic variations (SNPs, mutations and methylations) in PCR amplicons, particularly when only tiny samples are available (10-15). In HRM-designated instruments, the decrease in fluorescence caused by the transition of dsDNA to ssDNA with an increase in temperature is carefully monitored. With the aid of tailor-made analysis software, different genetic variants are discriminated by their characteristic melting curves. When melted in the presence of a saturating intercalating fluorescent dye, such as LCGreen I or Styo 9, and with the acquisition of fluorescence data over small temperature increments, amplicons containing different sequences are discriminated according to the melting transition of the PCR product and the resulting melt curve shape. Certain studies have validated the use of HRM as a method for scanning somatic mutations in p53. It is sensitive, rapid and cost effective, and markedly 
reduces the amount of sequencing required in the mutational study of p53, and thereby the cost of these studies (16-19).

Worldwide, breast cancer comprises $10.4 \%$ of all incidences of cancer among women, making it the second most common type of non-skin cancer (after lung cancer) and the fifth most common cause of cancer-related death (20). Epithelial proliferation of the breast encompasses a variety of proliferative and pre-cancerous lesions, which have to potential to progress to carcinoma. Those formed in the terminal of the ductal units are categorized as UDH, ADH and DCIS (21). To clarify genetic alterations in breast carcinogenesis, we aimed to investigate p53 mutations and its expression in a large number of non-invasive breast lesions, including UDH, ADH and DCIS samples, using HRM and immunohistochemistry.

\section{Materials and methods}

Subjects and samples. Fresh breast tissue samples were collected during surgical resection at the Department of Breast Surgery, the First Affiliated Hospital of China Medical University, China, between June 2007 and December 2009, including pure UDH $(n=40), \operatorname{ADH}(n=130)$ without DCIS, or DCIS $(n=70)$ without invasive breast cancer. The samples were frozen in liquid nitrogen and then stored at $-80^{\circ} \mathrm{C}$ until DNA extraction. The age range was $18-82$ years (mean 39.8 ). The study was approved by the regional ethics committee of China Medical University. Two pathologists independently reviewed each case and finally reached a unanimous diagnosis. Pathology classification was conducted according to the WHO criteria (22).

HRM assay. For each case, two H\&E-stained slides of fresh frozen samples were used as guides to verify and locate the $\mathrm{ADH}$ and DCIS lesions. Genomic DNA was extracted from 140 cases among the 240 fresh frozen tissue samples by the phenol-chloroform method. PCR primers were designed for the flanking site of exons 5, 6, 7 and 8 of the $p 53$ gene (Table I) and synthesized by Sangon Ltd. (Shanghai, China). The DNA samples were further diluted to a concentration of $10 \mathrm{ng} / \mu \mathrm{l}$ for PCR. The PCR reaction mixture $(20 \mu \mathrm{l})$ contained $10 \mathrm{ng}$ genomic

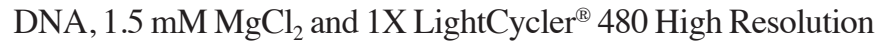
Master Mix (Roche Diagnostics, Mannheim, Germany). Duplicate PCRs and the HRM analysis were conducted on a LightCycler ${ }^{\circledR} 480$ PCR system (Roche Diagnostics). The PCR profile was: an initial hold at $95^{\circ} \mathrm{C}$ for $15 \mathrm{~min}$, followed by 45 cycles of denaturation at $95^{\circ} \mathrm{C}$ for $10 \mathrm{sec}$, annealing at $60^{\circ} \mathrm{C}$ for $10 \mathrm{sec}$ and extension at $72^{\circ} \mathrm{C}$ for $25 \mathrm{sec}$. After the latter run, the sample was held at $95^{\circ} \mathrm{C}$ for $1 \mathrm{~min}$, at $40^{\circ} \mathrm{C}$ for $1 \mathrm{~min}$ and then at $65^{\circ} \mathrm{C}$ for $1 \mathrm{sec}$. This was followed by a melt step of $65-95^{\circ} \mathrm{C}$ in $1^{\circ} \mathrm{C}$ increments, pausing for $1 \mathrm{sec}$ per step to generate the melt curve. Roche LightCycler ${ }^{\circledR} 480$ software (ver 1.5) was used to calculate the melt peaks by plotting the negative first derivative of the primary melt curve (fluorescence vs. temperature).

Sequence analysis of HRM products. Samples with the p53 variant-scanning panels whose melting profile deviated from that of the controls (both first-pass analysis and co-amplification) were recovered from the melt profiling plate for DNA sequence analysis, purified from gel using the QIAquick gel purification kit (Qiagen), and then subjected to automated sequencing (BigDye Terminator version 3.1;
Table I. p53 primers and PCR annealing temperatures.

\begin{tabular}{llc}
\hline Exon & \multicolumn{1}{c}{ Sequence $\left(5^{\prime} \rightarrow 3^{\prime}\right)$} & Size $(\mathrm{bp})$ \\
\hline 5 & $\begin{array}{l}\text { Fwd: TTC CTC TTC CTG CAG TAC TC } \\
\text { Rev: CAG CTG CTC ACC ATC GCT AT }\end{array}$ & 210 \\
& Fwd: CAC TGA TTG CTC TTA GGT CT & 144 \\
7 & Rev: AGT TGC AAA CCA GAC CTC AG & \\
7 & Fwd: GTG TTA TCT CCT AGG TTG GC & 144 \\
& Rev: CAA GTG GCT CCT GAC CTG GA & \\
8 & Fwd: CCT ATC CTG AGT A GT GGT AA & 165 \\
& Rev: TCC TGC TTG CTT ACC TCG CT & \\
\hline
\end{tabular}

Applied Biosystems) in both directions using the PCR primers. Sequences were analyzed using Mutation Surveyor 3.1 software (SoftGenetics, State College, PA, USA).

Immunohistochemistry. For immunohistochemical analysis, 4- $\mu$ m-thick sections of 240 formalin-fixed, paraffin-embedded specimens were deparaffinized with xylene and rehydrated through an alcohol gradient. Immunohistochemical staining was performed with the streptavidin peroxidase system (Ultrasensitive $^{\mathrm{TM}}$; Maixin-Bio, P.R. China) according to the manufacturer's instructions with a primary p53 specific antibody (DO-7, dilution 1:100; Santa Cruz Biotechnology, USA). For the negative control, sections were treated with $0.01 \mathrm{~mol} / 1$ phosphate-buffered saline instead of the primary antibody. A slide was considered negative or positive according to the absence or presence of positive staining: no staining or $<10 \%$ of total cells positive for $\mathrm{p} 53$ was considered negative; $\geq 10 \%$ of total cells positive for p53 was considered positive staining.

Statistical analysis. Differences between the positive rates were evaluated using Fisher's exact test. Analyses were performed using SPSS 13.0 statistical software for Windows. A P-value of $<0.05$ was considered statistically significant.

\section{Results}

A clear definition of the presence of somatic mutations in a sample was achievable by the comparison of the profile with wild-type DNA. Sequencing analysis was performed in all samples using the same PCR products after melting analysis. Figs. 1 and 2 display the results of HRM and sequencing analysis. Examples of HRM and melting profiles obtained from $\mathrm{ADH}$ and DCIS carried somatic mutations of exons 5-8 of p53 (Table II). We found no mutations in 40 cases of UDH, one mutation in $8(12.7 \%)$ of 63 cases of $\mathrm{ADH}$, and at least one mutation in $8(21.6 \%)$ of 37 cases of DCIS, with one of the cases harboring two mutations simultaneously. Frequent p53 mutations were found in DCIS compared to ADH ( $\mathrm{P}<0.05$, Table III).

Fig. 3 displays the immunohistochemical staining of p53 protein in UDH, ADH and DCIS with the antibody against wild-type and mutant p53.p53 protein was positively expressed in the nuclei of ADH and DCIS. None of the 40 cases of UDH, 19 of 130 cases $(14.6 \%)$ of ADH and 22 of 70 cases $(31.4 \%)$ of DCIS showed p53 protein expression. There was a significant 
A

Normalized and shifted melting curves

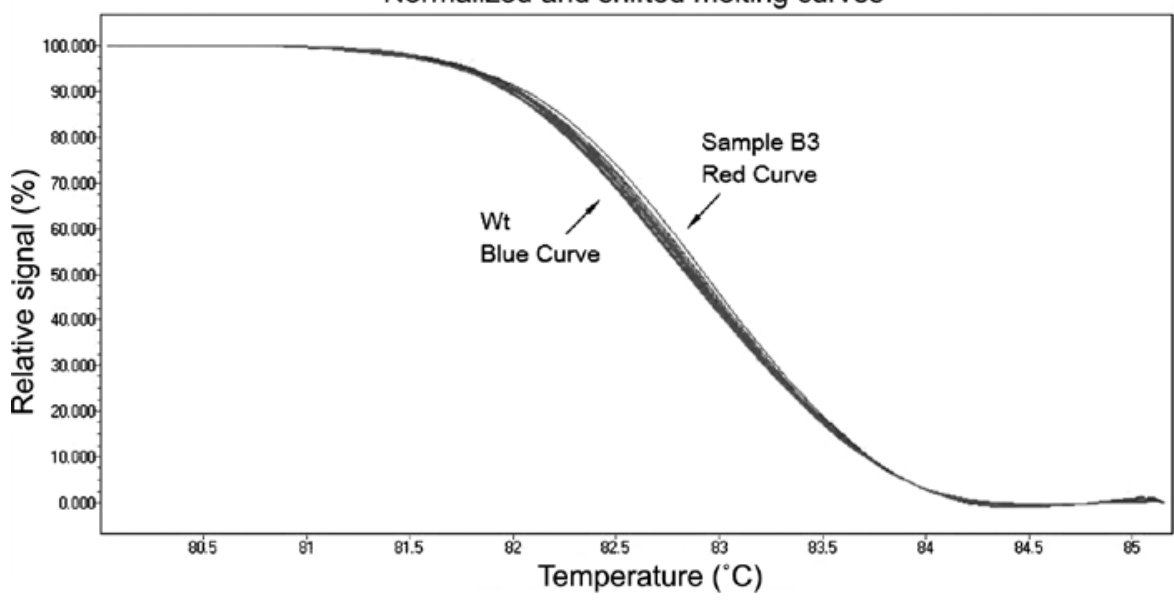

B Normalized and temp-shifted difference plot

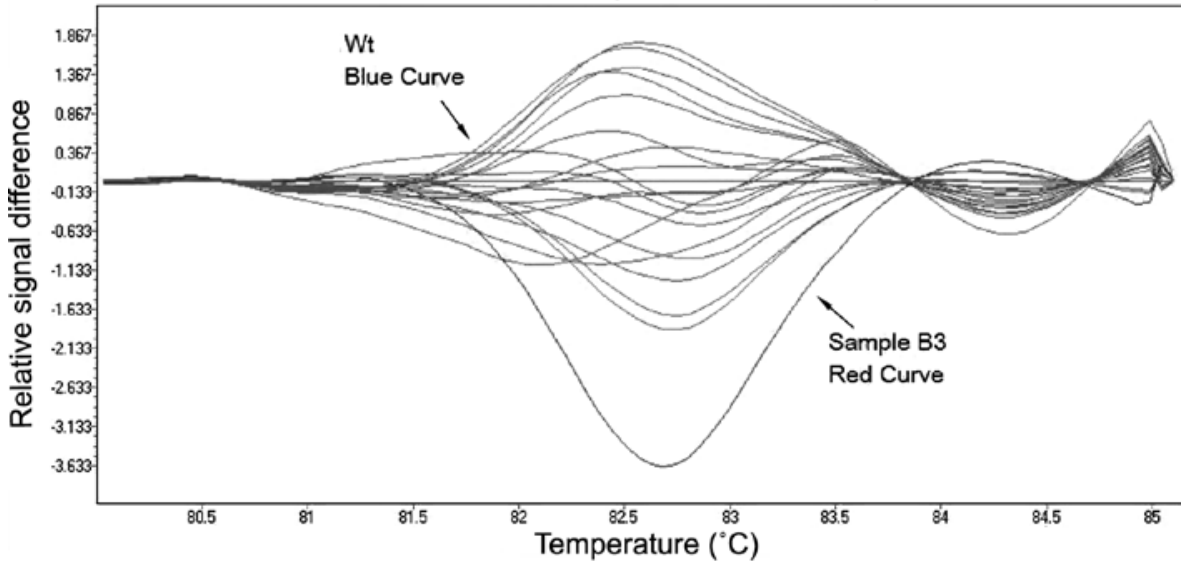

C

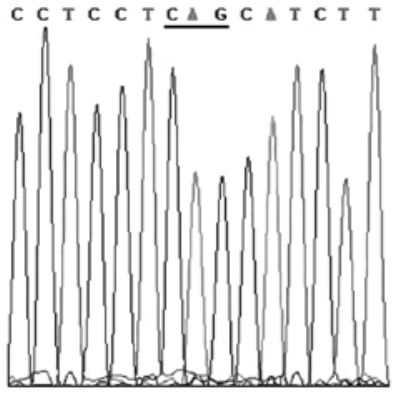

D

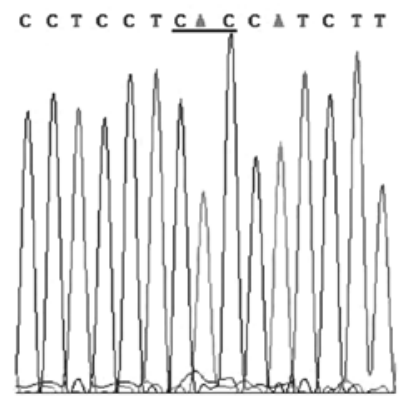

Figure 1. Screening of DNA samples of ADH for somatic mutations of p53 exon 6. (A) Normalized and temperature-shifted melting curves. (B) Substractive difference plots. (C) Sequencing trace for the wild-type of exon 6. (D) A mutation in exon 6 in sample B3 as demonstrated by sequencing analysis, $\mathrm{CAG} \rightarrow \mathrm{CAC}(\mathrm{G} 192 \mathrm{H})$.

difference between the p53 protein expression of DCIS and $\mathrm{ADH}(\mathrm{P}<0.05$, Table III).

In 140 cases of non-invasive breast lesions, $10.7 \%(15 / 140)$ had both p53 expression and mutations, $84.3 \%$ (118/140) had neither mutations nor expression, $4.3 \%$ (6/140) had expression without mutations, and 1 had a p53 mutation without its expression. p53 expression was closely linked to p53 mutations (Table IV).

\section{Discussion}

Mutations of p53 during carcinogenesis may lead to an increased stability of the originally unstable p 53 proteins, and p53 protein accumulation has been interpreted as a result of p53 mutation in several studies $(1-5,23)$. Many early investi- gators have found a 95\% rate of p53 mutation in exons 5-8, which is highly conserved through evolution, and presumably of functional importance. Although p53 mutations and protein expression have frequently been observed in invasive breast cancer and are implicated in its development, only a few studies have reported alterations of p53 in pre-invasive breast lesions (24-27). The results of these studies differed significantly, particularly in the case of $\mathrm{ADH}$. Done et al $(24,25)$ found that approximately $10 \%$ of DCIS carried a p53 missense mutation, and no mutations were identified in microdissected foci of epithelial hyperplasia, including one sample with atypia, suggesting that p53 mutations usually occur before the invasion of breast carcinomas. It should be noted that the authors only examined one sample of epithelial hyperplasia with atypia in their study. Keohavong et al (26) 

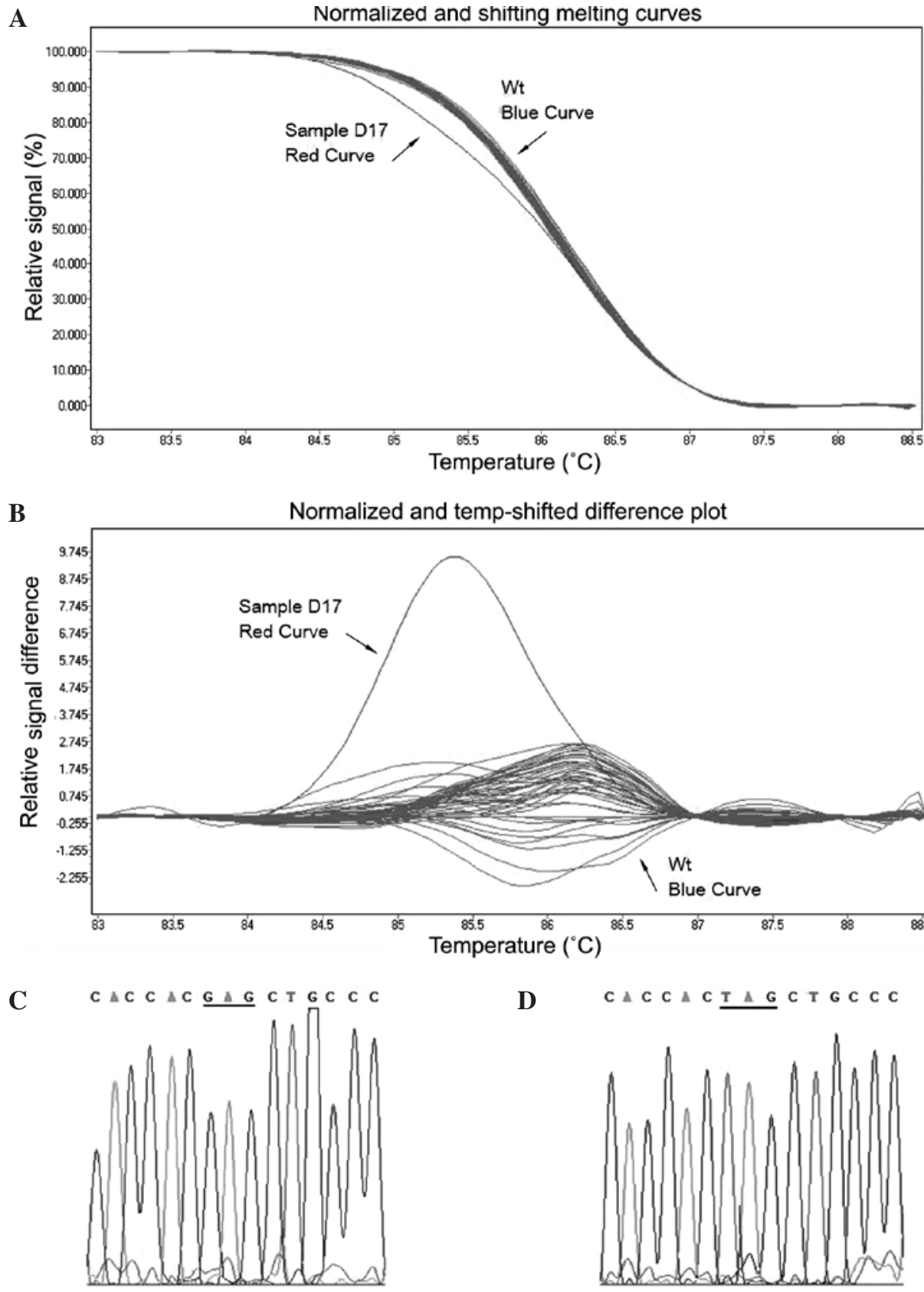

Figure 2. Screening of DNA samples of DCIS for somatic mutations of p53 exon 8. (A) Normalized and temperature-shifted melting curves. (B) Substractive difference plots. (C) Sequencing trace for the wild-type of exon 8. (D) A mutation in exon 8 in sample D17 was demonstrated by sequencing analysis, GAG $\rightarrow$ TAG(G298END).

combined tissue microdissection and SSCP to investigate p53 mutations in paraffin-embedded breast tissue sections, including 6 cases of DCIS and 10 of ADH. p53 mutations were detected in 3 cases of DCIS and in 5 cases of ADH, indicating that p53 is genetically altered not only in DCIS, but also in ADH. However, data remain scarce, and it is necessary to further investigate p53 mutations and expression in non-invasive breast ADH and DCIS using a large sample, including a number of non-invasive breast lesions.

HRM has high sensitivity and specificity, with a performance as good as, if not better than, other commonly used mutation scanning techniques (28). It is a closed tube system that not only reduces the potential for contamination, but also increases sample throughput, as it is not necessary to physically separate the DNA molecules. HRM furthermore offers significant savings in cost and turnaround time, and is an attractive choice for p53 mutation scanning, especially in high-throughput environments. Sonia et al (16) undertook mutation screening of the entire p53 locus by HRM and direct sequencing using a set of 47 samples, and found the sensitivity and specificity of HRM for sequence variant detection to be 1.0 and 0.83 . These results suggest that HRM provides sensitive assays for the detection of new sequence variants and the genotyping of known polymorphisms.

Here, we examined mutations of p53 exons 5-8 by HRM, and found its mutations in 16 samples. Sequence analysis indicated that 1 case was a nonsense mutation and 15 cases were missense mutations. p53 gene mutations occurred in $12.7 \%$ of the ADH samples and $21.6 \%$ of DCIS, but did not occur in UDH. 
Table II. p53 mutation and expression analysis of ADH and DCIS.

\begin{tabular}{|c|c|c|c|c|c|c|}
\hline \multirow[t]{2}{*}{ Simple ID } & \multirow[t]{2}{*}{ Types } & \multicolumn{4}{|c|}{ HRM and sequencing results } & \multirow[t]{2}{*}{ p53 protein expression } \\
\hline & & HRM & Exon mutation & Predicted effect & No. of cited db & \\
\hline B3 & $\mathrm{ADH}$ & MUT & 6, CAG-CAC & G192H & 5 & + \\
\hline B8 & $\mathrm{ADH}$ & MUT & 6, СCC-СТC & P219L & 7 & + \\
\hline A1 & $\mathrm{ADH}$ & MUT & 8, ACA-CCA & $\mathrm{T} 284 \mathrm{P}$ & 12 & + \\
\hline A13 & $\mathrm{ADH}$ & MUT & 5, CGC-CAC & $\mathrm{R} 175 \mathrm{H}$ & 1,262 & + \\
\hline A22 & $\mathrm{ADH}$ & MUT & 7, GGC-GAC & G245D & 188 & + \\
\hline A 23 & $\mathrm{ADH}$ & MUT & 7, ATG-ATA & M237I & 126 & + \\
\hline $\mathrm{C} 1$ & $\mathrm{ADH}$ & MUT & 8, GTT-GCT & V274A & 21 & + \\
\hline C5 & $\mathrm{ADH}$ & MUT & 6, CAT-CCT & H193P & 19 & + \\
\hline C6 & $\mathrm{ADH}$ & MUT & 6, no mutation & No & No & - \\
\hline D1 & DCIS & MUT & 7, TCC-TGC & S241C & 37 & + \\
\hline D7 & DCIS & MUT & 8, CGT-TGT & A273C & 744 & + \\
\hline D9 & DCIS & MUT & 8, GAC-AAC & $\mathrm{D} 281 \mathrm{~N}$ & 39 & + \\
\hline D10 & DCIS & MUT & $\begin{array}{l}\text { 6, CTT-CGT } \\
6, \text { GTG-ATG }\end{array}$ & $\begin{array}{l}\text { L194R } \\
\text { V216M }\end{array}$ & $\begin{array}{l}69 \\
80\end{array}$ & + \\
\hline D11 & DCIS & MUT & 5, CCC-CAC & $\mathrm{P} 151 \mathrm{H}$ & 62 & + \\
\hline D17 & DCIS & MUT & 8, GAG-TAG & G298END & 76 & - \\
\hline D21 & DCIS & MUT & 7, CGG-CAG & R248Q & 952 & + \\
\hline D25 & DCIS & MUT & 5, CAT-CGT & H179R & 161 & + \\
\hline
\end{tabular}

No. of cited db, number of times the mutation has been found in human cancers in the p53 database.
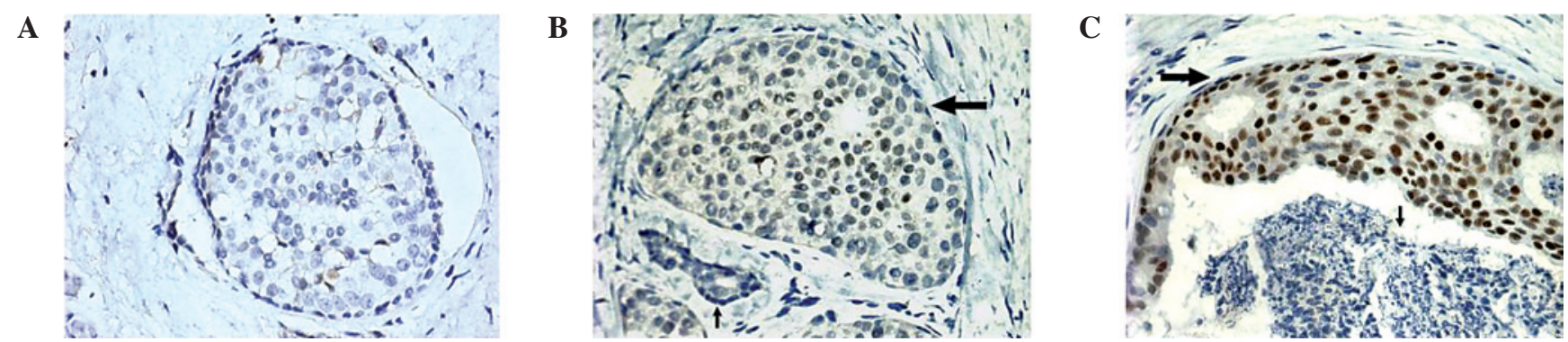

Figure 3. Immunohistochemical staining of p53 protein in non-invasive breast lesions. (A) p53-negative staining in UDH. (B) p53-positive staining in ADH. The big arrow indicates a breast duct filled with cells with atypical hyperplasia. The cells are fairly identical in size and shape. p53 positivity was observed in some nuclei $(>10 \%)$. The small arrow indicates a normal duct without p53 expression. (C) p53-positive staining in DCIS. The big arrow indicates a DCIS with positive staining of p53 in the nuclei $(>10 \%)$. The small arrow indicates necrosis in the DCIS.

Table III. Mutation and expression of p53 in breast carcinogenesis.

\begin{tabular}{lcccc}
\hline Groups & \multicolumn{2}{c}{ p53 mutation } & \multicolumn{2}{c}{ p53 expression } \\
\cline { 2 - 5 } & Total no. & No. $(\%)$ & Total no. & No. $(\%)$ \\
\hline UDH & 40 & $0(0.0)$ & 40 & $0(0.0)$ \\
ADH & 63 & $8(12.7)$ & 130 & $19(14.6)$ \\
DCIS & 37 & $8(21.6)^{\mathrm{a}}$ & 70 & $22(31.4)^{\mathrm{a}}$ \\
\hline
\end{tabular}

${ }^{\mathrm{P}}<0.01$, compared to $\mathrm{ADH}$.

Immunohistochemically, p53 protein was not expressed in UDH, but was observed in $14.6 \%$ of ADH and $31.4 \%$ of DCIS samples. Cases with a nonsense p53 mutation had no p53 expression. p53 expression was closely linked to p53 mutations in non-invasive breast lesions, in agreement with the interpretation of mutant p53 protein accumulation as a result 
Table IV. Comparison of p53 expression with its mutations in breast lesions.

\begin{tabular}{lrrr}
\hline p53 mutation & \multicolumn{2}{c}{$\mathrm{p} 53$ expression } & Total \\
\cline { 2 - 3 } & + & - & \\
\hline+ & 15 & 1 & 16 \\
- & 6 & 128 & 124 \\
Total & 21 & 119 & 140 \\
\hline
\end{tabular}

$\mathrm{P}<0.01$.

of its mutation. Additionally, there was a gradual increase in the incidence of p53 mutations and its expression from UDH to $\mathrm{ADH}$ and to DCIS, supporting the hypothesis that p53 mutations and subsequent accumulation may be involved in the tumorigenesis of breast tissue as an early event in $\mathrm{ADH}$. The low frequency of p53 mutations in ADH compared to DCIS also supports the epidemiological evidence that these lesions have distinct differences, and may in part explain the different relative risks of invasive carcinoma.

In summary, p53 mutations and consequent protein accumulation may be involved in breast tumorigenesis. It may be useful to monitor genetic alterations and aberrant p53 expression in pre-cancerous lesions of the breast.

\section{Acknowledgements}

This study was supported by the National Natural Science Foundation of China (No. 30950009). J.F. and M.X.Y. designed the research and wrote the paper. M.X.Y. and F.C.F. collected the breast lesion tissues and carried out the experiments. W.J. and Y.F. analyzed the data.

\section{References}

1. Zhang $\mathrm{Y}$ and $\mathrm{Lu} \mathrm{H}$ : Signaling to p53: ribosomal proteins find their way. Cancer Cell 16: 369-377, 2009.

2. Meek DW: Tumour suppression by p53: a role for the DNA damage response? Nat Rev Cancer 9: 714-723, 2009.

3. Rohan TE, Li SQ, Hartwick R and Kandel RA: p53 alterations and protein accumulation in benign breast tissue and breast cancer risk: a cohort study. Cancer Epidemiol Biomarkers Prev 15: 1316-1323, 2006.

4. Blattner C: Regulation of p53: the next generation. Cell Cycle 7: 3149-3153, 2008

5. Bailey SL, Gurley KE, Hoon-Kim K, Kelly-Spratt KS and Kemp CJ: Tumor suppression by p53 in the absence of Atm. Mol Cancer Res 6: 1185-1192, 2008.

6. Zhang Z, Wang M, Wu D, Wang M, Tong N, Tian Y and Zhang Z: P53 codon 72 polymorphism contributes to breast cancer risk: a meta-analysis based on 39 case-control studies. Breast Cancer Res Treat 120: 509-517, 2010.

7. Rossner P Jr, Gammon MD, Zhang YJ, Terry MB, Hibshoosh H, Memeo L, Mansukhani M, Long CM, Garbowski G, Agrawal M, Kalra TS, Gaudet MM, Teitelbaum SL, Neugut AI and Santella RM: Mutations in p53, p53 protein overexpression and breast cancer survival. J Cell Mol Med 13: 3847-3857, 2009.

8. Sarid D, Ron IG, Shoshan L, Barnea I, Shina S, Baratz M, Greenberg J, Merimsky O, Ben-Yosef R, Lev-Ari S, Keidar Y and Yaal-Hahoshen N: Invasive breast cancer treated with taxol and epirubicin neo-adjuvant chemotherapy: the role in the outcome of the 'crosstalk' between Erb receptors and p53. Anticancer Res 28: $3147-3152,2008$
9. Matsukuma S, Yoshihara M, Kasai F, et al: Rapid and simple detection of hot spot point mutations of epidermal growth factor receptor, BRAF, and NRAS in cancers using the loop-hybrid mobility shift assay. J Mol Diagn 8: 504-512, 2006.

10. Heideman DA, Thunnissen FB, Doeleman M, Kramer D, Verheul HM, Smit EF, Postmus PE, Meijer CJ, Meijer GA and Snijders PJ: A panel of high resolution melting (HRM) technologybased assays with direct sequencing possibility for effective mutation screening of EGFR and K-ras genes. Cell Oncol 31: 329-333, 2009.

11. Liu ZM, Liu LN, Li M, Zhang QP, Cheng SH and Lu S: Mutation detection of KRAS by high-resolution melting analysis in Chinese with gastric cancer. Oncol Rep 22: 515-520, 2009.

12. Audrezet MP, Dabricot A, Le Marechal C and Ferec C: Validation of high-resolution DNA melting analysis for mutation scanning of the cystic fibrosis transmembrane conductance regulator (CFTR) gene. J Mol Diagn 10: 424-434, 2008.

13. Whittall RA, Scartezini M, Li K, Hubbart C, Reiner Z, Abraha A, Neil HA, Dedoussis G and Humphries SE: Development of a high-resolution melting method for mutation detection in familial hypercholesterolaemia patients. Ann Clin Biochem 47: 44-55, 2010.

14. Do H, Krypuy M, Mitchell PL, Fox SB and Dobrovic A: High resolution melting analysis for rapid and sensitive EGFR and KRAS mutation detection in formalin fixed paraffin embedded biopsies. BMC Cancer 8: 142, 2008.

15. Margraf RL, Mao R, Highsmith WE, Holtegaard LM and Wittwer CT: Mutation scanning of the RET protooncogene using high-resolution melting analysis. Clin Chem 52: 138-141, 2006.

16. Garritano S, Gemignani $F$, Voegele $C$, Nguyen-Dumont $T$, Le Calvez-Kelm F, De Silva D, Lesueur F, Landi S and Tavtigian SV: Determining the effectiveness of High Resolution Melting analysis for SNP genotyping and mutation scanning at the TP53 locus. BMC Genet 10: 5, 2009.

17. Bastien R, Lewis TB, Hawkes JE, Quackenbush JF, Robbins TC, Palazzo J, Perou CM and Bernard PS: High-throughput amplicon scanning of the TP53 gene in breast cancer using high-resolution fluorescent melting curve analyses and automatic mutation calling. Hum Mutat 29: 757-764, 2008.

18. Krypuy M, Ahmed AA, Etemadmoghadam D, Hyland SJ; Australian Ovarian Cancer Study Group, DeFazio A, Fox SB, Brenton JD, Bowtell DD and Dobrovic A: High resolution melting for mutation scanning of TP53 exons 5-8. BMC Cancer 7: 168, 2007.

19. Seth R, Keeley J, Abu-Ali G, Crook S, Jackson D and Ilyas M: The putative tumour modifier gene ATP5A1 is not mutated in human colorectal cancer cell lines but expression levels correlate with TP53 mutations and chromosomal instability. J Clin Pathol 62: 598-603, 2009

20. Boyle P and Levin B (eds): World Cancer Report. International Agency for Research on Cancer, Lyon, France, 2003.

21. Zhou CJ, Zhang QH, Zhang TG, Sun SZ, Li H, Wang Y and Liu ZY: Expression of ER, Ki-67 and cylinD1 in the pre-cancerous breast of Chinese patients. Pathol Oncol Res 15: 153-158, 2009.

22. Tavassoli FA: Breast pathology: rationale for adopting the ductal intraepithelial neoplasia (DIN) classification. Nat Clin Pract Oncol 2: 116-117, 2005.

23. Chan WY, Cheung KK, Schorge JO, Huang LW, Welch WR, Bell DA, Berkowitz RS and Mok SC: Bcl-2 and p53 protein expression, apoptosis, and p53 mutation in human epithelial ovarian cancers. Am J Pathol 156: 409-417, 2000.

24. Done SJ, Arneson CR, Ozçelik H, Redston M and Andrulis IL: P53 protein accumulation in non-invasive lesions surrounding p53 mutation positive invasive breast cancers. Breast Cancer Res Treat 65: 111-118, 2001.

25. Done SJ, Arneson NC, Ozçelik H, Redston M and Andrulis IL: p53 mutations in mammary ductal carcinoma in situ but not in epithelial hyperplasias. Cancer Res 58: 785-789, 1998.

26. Keohavong P, Gao WM, Mady HH, Kanbour-Shakir A and Melhem MF: Analysis of p53 mutations in cells taken from paraffin-embedded tissue sections of ductal carcinoma in situ and atypical ductal hyperplasia of the breast. Cancer Lett 212: 121-130, 2004.

27. Pihan GA, Wallace J, Zhou Y and Doxsey SJ: Centrosome abnormalities and chromosome instability occur together in preinvasive carcinomas. Cancer Res 63: 1398-1404, 2003.

28. Taylor CF and Taylor GR: Current and emerging techniques for diagnostic mutation detection: an overview of methods for mutation detection. Methods Mol Med 92: 9-44, 2004. 